\title{
Regulatory RNAs in Planarians
}

\author{
Kamila Pawlicka ${ }^{\bowtie}$, Patrick M. Perrigue ${ }^{\bowtie}$ and Jan Barciszewski ${ }^{\bowtie}$ \\ Institute of Bioorganic Chemistry, Polish Academy of Sciences, Poznań, Poland
}

The full scope of regulatory RNA evolution and function in epigenetic processes is still not well understood. The development of planarian flatworms to be used as a simple model organism for research has shown a great potential to address gaps in the knowledge in this field of study. The genomes of planarians encode a wide array of regulatory RNAs that function in gene regulation. Here, we review planarians as a suitable model organism for the identification and function of regulatory RNAs.

Key words: planarians, RNAi, miRNA, regeneration, stem cells

Received: 04 June, 2016; revised: 23 June, 2016; accepted: 14 July, 2016; available on-line: 02 November, 2016

\section{INTRODUCTION}

Planarians are non-parasitic invertebrate flatworms that are representative of the Platyhelminthes phylum. They are relatively simple organisms that display bilateral symmetry, three germ layers (triploblastic), along with basic organ systems. It has been long documented for over a century that planarians have a remarkable regenerative capacity including the ability to regenerate from amputated pieces of tissue (Reddien \& Alvarado, 2004). A worm can be cut horizontally, vertically or even into a small fragment that is $1 / 279^{\text {th }}$ of the original size to recreate the complete organism (Alvarado, 2012). Remarkably, the tail fragments are able to replace the animal's entire brain and head region in seven days. Once regeneration is completed, planarians can remodel their body to regain the correct proportion. These features make planarians a prime model for studying the molecular genetics of regeneration, in contrast to other invertebrate model organisms such as $C$. elegans and D. melanogaster that have limited regenerative capabilities.

Over the past 20 years, molecular approaches have been applied to research on planarians (Newmark \& Alvarado, 2002). The molecular toolkit for studying gene expression and function in planarians now includes a whole-mount in situ hybridization, immunocytochemistry, cell sorting, RNAi and RNA-sequencing. As a result of this development in technology, planarians have become a well-known model organism used worldwide for studying the biology of stem cells, regeneration, organogenesis and germ line development (Aboobaker, 2011; Lobo et al., 2012; Pellettieri \& Alvarado, 2007; Rink, 2013; Roberts-Galbraith \& Newmark, 2015; Rossi et al., 2008). Planarians have adult pluripotent stem cells called neoblasts that have been extensively studied for their role in the regeneration process. Neoblasts comprise approximately $30 \%$ of the cells in the adult organism and migrate to the sites of injury, divide, and give rise to progeny that differentiate in order to replace the missing structures (Eisenhoffer et al., 2008; Sanchez-Alvarado,
2006). Experiments using X-rays also proved that neoblasts are the only dividing cells, as irradiated planarians are unable to regenerate (Newmark \& Alvarado, 2000).

There are a number of different planarian species available for laboratory research. The most widely used is a clonal line of the Schmidtea mediterranea species which was generated via repeated rounds of cutting and regeneration (Alvarado, 2003; Alvarado \& Kang, 2005). S. mediterranea are diploid, exist in sexual and asexual strains and their genome has been sequenced and annotated (Alvarado et al., 2002). The genome size of S. mediterranea is nearly one third of the human genome and almost $80 \%$ of the known S. mediterranea genes have human orthologs. Some of these genes include conservation of key regulators of the small interfering RNA (siRNA) pathway (Resch \& Palakodeti, 2012). Due to the unique phylogenetic position of planarians, the origins and mechanisms of regulatory RNAs can be investigated while maintaining enough genetic similarity to humans.

Regulatory RNAs play an important role in the epigenetic processes that control differentiation and development by altering gene expression (Morris \& Mattick, 2014). The majority of regulatory RNAs are non-coding and therefore do not produce protein. The types of regulatory RNAs can differ in their size, function and biogenesis pathway. For example, small non-coding RNAs such as miRNAs (18-25 nucleotides) have the potential to downregulate gene expression based upon sequence complimentary to a target RNA sequence. miRNAs bind to the 3' untranslated regions of target mRNAs and either induce mRNA degradation or block translation, resulting in gene silencing (He \& Hannon, 2004). The miRNA biogenesis is composed of at least two sequential steps and begins with a long RNA transcript termed a primary miRNA (pri-miRNA) (Denli et al., 2004). The first processing step is mediated by the DROSHA microprocessor complex which shortens pri-miRNA into a $\sim 70$ 100 nucleotide hairpin structure termed a pre-miRNA. Sequentially, the pre-miRNA is then translocated to the cytosol where final processing is mediated by a second, double-strand specific ribonuclease, known as Dicer. This produces a mature miRNA capable of being incorporated into the RISC complex for gene silencing. Here, we review the topic of RNAi as a tool for genetic screening, as well as the future directions of studying miRNA and other regulatory RNA types in planarians. The studies thus far suggest that many regulatory RNA sequences are highly conserved along with some that are potentially unique to planarians. The expression pattern of some identified regulatory RNAs indicates their func-

e-mail: pawlicka_kamila@wp.pl (KP); pperrigue@ibch.poznan.pl (PP); Jan.Barciszewski@ibch.poznan.pl (JB)

Abbreviations: S. mediterranea, Schmidtea mediterranea 


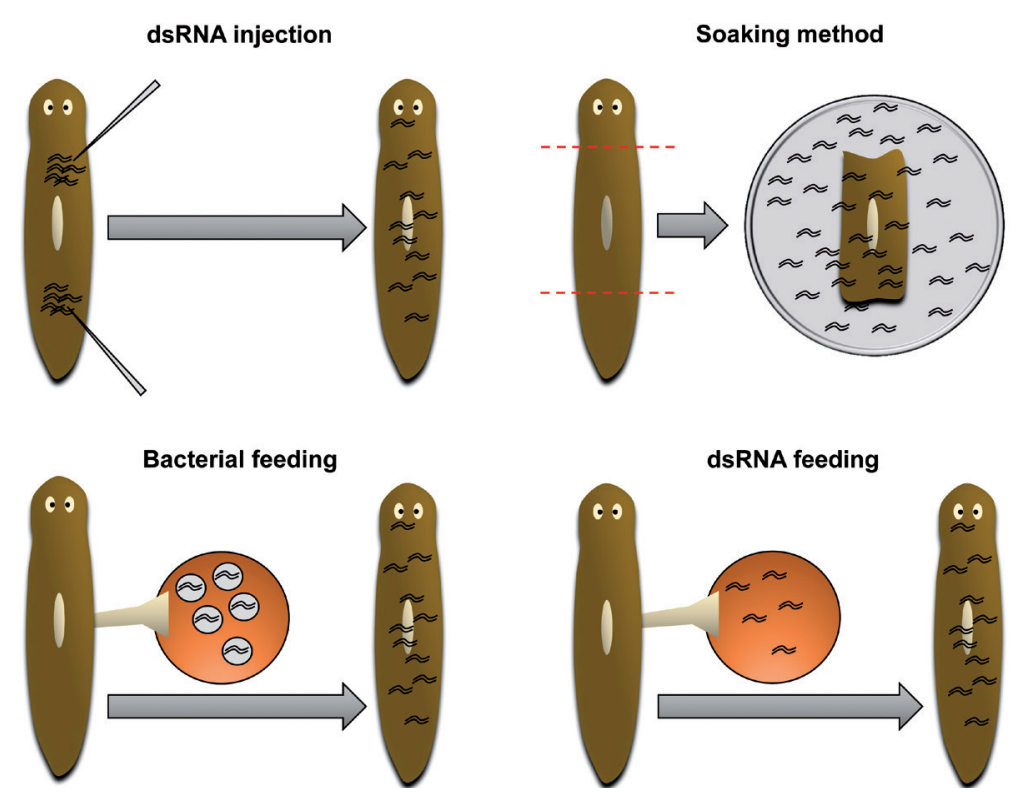

Figure 1. RNAi delivery methods for planarians.

Direct injection; a microinjection system is used to deliver dsRNA. Soaking method; decapitation and tail amputation with subsequent soaking of the worm's middle section in dsRNA solution. Bacterial feeding; worms eat food spiked with bacteria expressing dsRNA. dsRNA feeding; worms eat food spiked with dsRNA..

tion in regeneration, however a large portion of them are still to be determined.

\section{METHODS OF RNAi FOR GENETIC SCREENING}

One of the advantages of the $S$. mediterranea model is the ability to carry out large-scale gene inactivation screens using RNAi. This is particularly easy because RNAi can be delivered simply by feeding planarians with a dsRNA. Because the animal has a long vascular digestive tract, the ingested dsRNA reaches almost every cell to achieve a systemic RNAi effect. RNAi knockdown in planarians can yield defects in regeneration, tissue maintenance, and/or behavior. There are a large number of robust phenotypes that can often provide insight about a gene's function. For example, RNAi mediated knockdown of the gene nou-darake encoding a fibroblast growth factor receptor-related protein, led to an ectopic brain formation (Cebria et al., 2002). The effect of knocking down nou-darake over time produces worms with multiple sets of eyes along with complete brain structures in the trunk region. nou-darake, which means 'brains everywhere' in Japanese, is proposed to function as an inhibitor of brain formation by preventing the neuronal differentiation of neoblasts.

Processing of dsRNA involves the canonical RNAi pathway via cleavage by the protein dicer and further incorporation into the RISC complex for gene silencing. The RNAi methods in planarians have been evolving and improved over time (Fig. 1). Originally, it was demonstrated that RNAi could be delivered to planarians by micro-injection into the mesenchyme of the animal (Alvarado \& Newmark, 1999). This approach is very efficient and results in specific mRNA degradation within 6-24 hours after injection. Although this method shows satisfying effects, it is also time consuming and laborious, which makes it not practical for large scale RNAi studies. The damage caused by the needle tract may also affect the outcome and analysis of phenotypes related to regeneration.
A less invasive method of RNAi involves soaking planarian fragments in solution with dsRNA for several hours (Orii et al., 2003). This technique is simple and easy, however it requires large volumes of concentrated dsRNA $(0.1-0.5 \mu \mathrm{g} / \mu \mathrm{l})$, and is not useful in analyzing the homeostasis of intact planarians. Another alternative to the injection method has been using bacteria as the expression system and transporter of dsRNA (Newmark et al., 2003). Worms ingest an artificial food consisting of bacteria that express dsRNA, liver homogenate, ultra-low gelling agarose and food coloring for visualization of eating. This method was applied in the first largescale screen in planarians (Reddien et al., 2005a), however it is challenging to verify the quantity and quality of dsRNA expressed by the bacteria. Notably, enzyme deficient bacterial strains can be used to decrease the degree of dsRNA degradation caused by RNases (Timmons et al., 2001). Omitting the bacteria altogether and mixing in vitro-synthesized dsRNA with planarian food is another alternative (Rouhana et al., 2013). This has huge advantages because the quality and quantity of dsRNA can be easily measured. It is also cost-effective and has reduced labor and time requirements.

\section{GENE EXPRESSION ANALYSIS}

Without an observed phenotype it can be difficult to assess if RNAi against a target gene is working. Wholemount in situ hybridization protocols have been developed and optimized in order to visualize the gene expression patterns (Pearson et al., 2009). The method has been instrumental in defining cell-type specific markers, and assessing the RNAi efficiency in planarians. For example, a zinc finger transcription factor, Smed-ZicA is expressed in the cells that make up the anterior regenerating pole which is on the most tip part of the regenerating head (Vogg et al., 2014). Recently, various monoclonal antibodies have been developed in order to visualize protein expression in planarians. The detection of protein enhances the analysis of RNAi experiments, as well as helps to further characterize planarian cell populations by immunocytochemistry (Robb \& Alvarado, 2002; Ross et al., 2015). Thirty-two markers have been identified to distinguish the lineage progression between two main epithelial progenitor populations (Zhu et al., 2015). Two homeodomain transcription factor homologs, Smed-lhx1/5-1 and Smed-pitx, are required for the maintenance and regeneration of serotonergic neurons in planarians (Currie \& Pearson, 2013).

RNA deep sequencing is still a developing method that has many applications in molecular biology. RNA-seq was applied to planarians comparing the transcriptional landscape of head and tail fragments during regeneration (Kao et al., 2013). RNAi screening can be used in conjunction with RNA sequencing protocols for profiling of global gene expression. For example, a study by Cowles et al. used RNA-seq to identify 397 nervous system-related genes regulated by Collier/Olfactory 1/ 
Early B cell factor (Cowles et al., 2014). In searching for cells that show an altered phenotype after RNAi treatment, a cell sorting protocol has been developed that can be used not only to characterize cell populations, but also to separate them for further downstream applications (Kang \& Alvarado, 2009). A transcriptome analysis performed on isolated neoblasts revealed that expression of a specific set of one hundred and twenty-three genes is a conserved feature of pluripotency among different animal species (Labbe et al., 2012). Another study used cell sorting to isolate differentiated and neoblast cell types to examine the expression of thirty-three different transcription factors during neoblast differentiation (Scimone et al., 2014). Furthermore, single-cell transcriptional profiling from over a thousand individual neoblasts was used to directly compare the gene expression profile during homeostasis versus regeneration (van Wolfswinkel et al., 2014).

\section{miRNAs}

miRNAs are short RNA molecules that play an important role in the regulation of gene expression controlling biological outcomes. The function of miRNA regulation is conserved in planarians, as knockdown of Smed-Ago (a homolog of the Argonaute protein family), which is the key factor in miRNA activity, was shown to

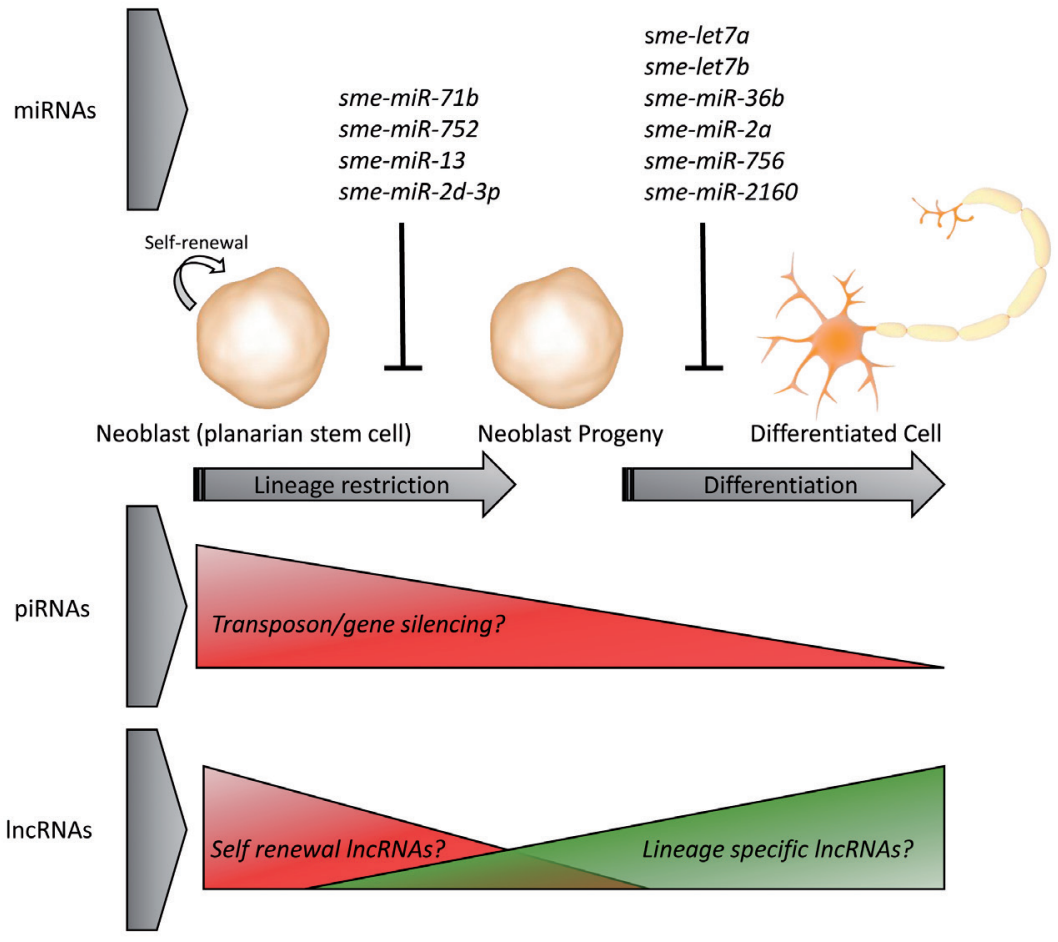

Figure 2. Regulatory RNAs have many functions in the neoblast maintenance.

There are a variety of miRNAs that are expressed to fine tune gene expression/pathways that regulate the proliferation and differentiation of neoblasts. sme-miR71b, miR752, miR13 , and $m i R-2 d-3 p$ were shown to be elevated in self-renewing neoblasts when compared to progenitor cells. Similar to what is observed in other animals, these miRNAs help to coordinate the lineage restriction in self-renewing neoblasts. In neoblast progeny, smelet-7a, let-7b, miR-36b, miR-2a, miR-756, and miR-2160 may promote differentiation by inhibiting the cell cycle regulators. piRNAs are predominately expressed in neoblasts and their expression decreases to promote lineage specification and differentiation. The conserved role of piRNA is in transposon/gene silencing, however this is unclear during neoblast maintenance. IncRNAs provide chromatin modifying complexes with their sequence specificity to up- or down-regulate genetic programs. Dynamic epigenetic modifications to histones and DNA are necessary for proper cell lineage specification and differentiation during regeneration. Certain IncRNAs may be temporally expressed and function in selfrenewal, while others are lineage specific for neoblast differentiation. stunt head regeneration (Li et al., 2011). Several studies have reported on the diversity of miRNA species in planea (Palakodeti et al., 2006). A sequence comparison of miRNAs showed that 54 are similar to members cur to be planarian-specific. Another study identified 21 sus asexual strain of S. mediterranea (Lu et al., 2009). Notably, the sexual strain of $S$. mediterranea is hermaphroditic to characterize these differentially expressed miRNAs gans and germ cells.

miRNA microarray chip analysis was used to study regention patterns of planarian miRNAs in the miRNAs were found to be elevated during the regeneration process, compared to five that were decreased. Of these miRNAs, the highest upregulated in the regenerating tissues were mir-13 and mir-756. Another study reported the expression patterns of 42 miRNAs during tissue regeneration (Gonzalez-Estevez et al., 2009). The me miRNAs were found to be expressed in neurons and in proximity to the location of neoblasts, suggesting that miRNAs may be involved in the regulation of neoblast differentiation during neurogenesis.

Interestingly, it was discovered that planarian neoblasts express let-7 miRNA family members (Friedlander et al., 2009; Gonzalez-Estevez et al., 2009). Biphasic expression patterns that govern the cell cycle transition step between self-renewal and differentiation in stem cells are tightly regulated by let-7 miRNA family members (Johnson et al., 2007; Roush \& Slack, 2008). Low levels of let-7 miRNA in cells have been proposed to maintain stemness, while high levels of let-7 determine cell specification and differentiation (Wulczyn et al., 2007). let-7 expression may show a similar pattern to what is seen in other stem cell models and may control proliferation and possibly the differentiation of neoblasts.

The Wnt signaling pathway is an evolutionarily conserved pathway that controls cell-fate, morphogenesis, and antero-posterior (AP) patterning (Petersen \& Reddien, 2009). The pathway is named after the Wnt family of secreted proteins that bind to and activate the Frizzled/LRP5-6 receptors found on the surface of cells. Canonical Wnt signal transduction involves translocation of $\beta$-catenin protein to the nucleus where it associates with Lef/Tcf transcriptional repressors, causing the derepression of transcriptional targets (MacDonald et al., 2009). In planarians, gene silencing of $\beta$-catenin-1 produces a phenotype consistent with deactivation of the Wnt pathway which 
is a complete loss of posterior and central identities, resulting in animals that are two-headed or sometimes hypercephalized (Petersen \& Reddien, 2008). With this rationale, it plausible that miRNAs that target key proteins of the Wnt signaling pathway would in turn regulate the $\mathrm{AP}$ axis patterning in planarians. For example, mir- 8 is implicated in the regulation of planarian regeneration polarity since its conserved function is to inhibit expression of the Tcf protein (Kennell et al., 2008). Other miRNAs that may potentially control aspects of the AP axis are members of the mir-124 family as these are up-regulated in the anterior regenerating tissue, but not in the posterior regenerating tissue (Sasidharan et al., 2013).

Several of the expression patterns for pri-miRNA in intact planarians are known, however mature miRNA expression data is needed to suggest the biological role of these miRNAs in the tissue. Development of RNA deep sequencing methods for use in $S$. mediterranea has contributed to the acceleration of mature miRNA species characterization ( $\mathrm{Lu}$ et al., 2009; Qin et al., 2012). As a result, over 208 novel miRNAs have been identified in planarians. Friedländer et al. analyzed the sequences of small RNAs in S. meditteranea and found 10 miRNAs to be enriched in neoblasts: sme-let7a, sme-let7b, sme-miR36b, sme-miR-2a, sme-miR-2d-3p, sme-miR-13, sme-miR-71b, sme-miR-752, sme-miR-756, and sme-miR-2160 (Friedlander et al., 2009). Collectively these studies implicate the importance of miRNAs and possibly other regulatory RNAs in the stem cell function and regeneration process (Fig. 2). Further characterization of the expression patterns and prediction of the target mRNAs for all of these miRNAs will provide insight into miRNA-mediated gene regulation and its role in the tissue regeneration.

\section{OTHER REGULATORY RNAs AND FUTURE DIRECTIONS}

Piwi-interacting RNA (piRNA) represent another class of regulatory RNAs that range from 26-32 nucleotides in length and are implicated in the regulation of transposon control, as majority of their sequences are antisense to transposon sequences (Thomson \& Lin, 2009; Weick \& Miska, 2014). The biogenesis of piRNAs and their function are regulated by PIWI proteins that mediate silencing via cleavage of the transcribed RNA. Together, both piRNA and PIWI proteins are co-expressed in the germ cells of a wide variety of animals, including $M$. musculus, C. elegans, and D. melanogaster (Juliano et al., 2011). The function of piRNA-mediated transposon silencing is implicated in the regulation of germ cells, however full elucidation of the mechanism is unclear.

There are at least three genes that code for $S$. mediterranea PIWI protein homologs, named Smedwi-1, Smedwi-2, and Smedwi-3 (Palakodeti et al., 2008; Reddien et al., 2005b). Interestingly, Smedwi proteins are predominantly expressed in neoblasts, which is cooborated by studies that show that piRNA expression is predominately restricted to neoblasts (Friedlander et al., 2009). RNAi knockdown of Smedwi-2 and Smedwi-3 produce animals that have homeostasis and regeneration defects, suggesting that piRNAs and their biogenesis is likely involved in the regulation and maintenance of planarian neoblasts (Palakodeti et al., 2008). In another study, Smedwi-1 and Smedwi-3 were shown to be required for proper localization of histone $\mathrm{H} 4 \mathrm{mRNA}$ to chromatoid bodies (Rouhana et al., 2014). Beyond transposon silencing, piRNAs are involved in transcriptional gene silencing, however this role remains poorly understood from a mechanistic point of view in neoblasts (Bamezai et al.,
2012). Future studies are needed using the $S$. mediterranea sexual strain to elucidate the functions and mechanisms of piRNA in transgenerational inheritance.

Long non-coding RNA (lncRNA) are 200 nucleotides in length and regulate chromatin, gene transcription and several aspects of translation (Fatica \& Bozzoni, 2014). Genome and RNA-sequence analysis uncovered evidence for transcription of lncRNAs from the mitochondrial genome of flatworms (Ross et al., 2016). lncRNA based mechanisms are implicated in the epigenetic regulation of stem cells and regeneration, however studies are needed to help in identifying novel lncRNA functions. S. mediterranea homologs for SET1/MLL family of histone methyltransferases (set1, mll1/2, trr1, trr2, mll51 and mll52), COMPASS (complex proteins associated with Set1), and COMPASS-like genes are critical factors in the epigenetic regulation of neoblasts. (Hubert et al., 2013). SET1/MLL family of histone methyltransferases are known to activate gene expression by methylating lysine 4 of histone H3 (Duncan et al., 2015; Li \& Kelly, 2011). Notably, SET1/MLL complexes bind to lncRNAs which are required for their recruitment to chromatin in order to activate the Hox gene expression during development. Conservation of this mechanism would suggest that certain lncRNAs may be required for planarian regeneration.

\section{Authors' contributions}

$\mathrm{KP}, \mathrm{PMP}$, and JB wrote the manuscript together.

\section{Competing interests}

The authors declare that they have no competing interests.

\section{Acknowledgements}

This publication was supported by the Polish Ministry of Science and Higher Education, under the KNOW program.

\section{REFERENCES}

Aboobaker AA (2011) Planarian stem cells: a simple paradigm for regeneration. Trends Cell Biol 21: 304-311. http://doi.org/10.1016/j. tcb.2011.01.005

Alvarado AS (2003) The freshwater planarian Schmidtea mediterranea: embryogenesis, stem cells and regeneration - Commentary. Curr Opin Genet Develop 13: 438-444. http://doi.org/10.1016/S0959$437 \mathrm{x}(03) 00082-0$

Alvarado AS, Kang H (2005) Multicellularity, stem cells, and the neoblasts of the planarian Schmidtea mediterranea. Exp Cell Res 306: 299-308. http://doi.org/10.1016/j.yexcr.2005.03.020

Alvarado AS, Newmark PA (1999) Double-stranded RNA specifically disrupts gene expression during planarian regeneration. Proc Natl Acad Sci U S A 96: 5049-5054. http://doi.org/10.1073/ pnas.96.9.5049

Alvarado AS, Newmark PA, Robb SMC, Juste R (2002) The Schmidtea mediterranea database as a molecular resource for studying platyhelminthes, stem cells and regeneration. Development 129: 5659-5665. http://doi.org/10.1242/dev.00167

Bamezai S, Rawat VPS, Buske C (2012) Concise Review: The PiwipiRNA axis: pivotal beyond transposon silencing. Stem Cells 30: 2603-2611. http://doi.org/10.1002/stem.1237

Cebria F, Kobayashi C, Umesono Y, Nakazawa M, Mineta K, Ikeo K, Gojobori T, Itoh M, Taira M, Alvarado AS, Agata K (2002) FGFR-related gene nou-darake restricts brain tissues to the head region of planarians. Nature 419: 620-624. http://doi.org/10.1038/ nature 01042

Cowles MW, Omuro KC, Stanley BN, Quintanilla CG, Zayas RM (2014) COE loss-of-function analysis reveals a genetic program underlying maintenance and regeneration of the nervous system in $\mathrm{Pla}$ narians. Plos Genetics 10: ARTN e1004746. http://doi.org/10.1371/ journal.pgen.1004746 
Currie KW, Pearson BJ (2013) Transcription factors lhx1/5-1 and pitx are required for the maintenance and regeneration of serotonergic neurons in planarians. Development 140: 3577-3588. http://doi. org/10.1242/dev.098590

Denli AM, Tops BBJ, Plasterk RHA, Ketting RF, Hannon GJ (2004) Processing of primary microRNAs by the Microprocessor complex. Nature 432: 231-235. http://doi.org/10.1038/nature03049

Duncan EM, Chitsazan AD, Seidel CW, Sanchez Alvarado A (2015) Set1 and MLL1/2 target distinct sets of functionally different genomic loci in vivo. Cell Rep 13: 2741-2755. http://doi. org/10.1016/j.celrep.2015.11.059

Eisenhoffer GT, Kang H, Alvarado AS (2008) Molecular analysis of stem cells and their descendants during cell turnover and regeneration in the planarian Schmidtea mediterranea. Cell Stem Cell 3: 327-339. http://doi.org/10.1016/j.stem.2008.07.002

Fatica A, Bozzoni I (2014) Long non-coding RNAs: new players in cell differentiation and development. Nat Rev Genet 15: 7-21. http://doi. org $/ 10.1038 / \operatorname{nrg} 3606$

Friedlander MR, Adamidi C, Han T, Lebedeva S, Isenbarger TA, Hirst M, Marra M, Nusbaum C, Lee WL, Jenkin JC, Alvarado AS, Kim JK, Rajewsky N (2009a) High-resolution profiling and discovery of planarian small RNAs. Proc Natl Acad Sci U S A 106: 11546-11551. http://doi.org/10.1073/pnas.0905222106

Friedlander MR, Adamidi C, Han T, Lebedeva S, Isenbarger TA, Hirst M, Marra M, Nusbaum C, Lee WL, Jenkin JC, Alvarado AS, Kim JK, Rajewsky N (2009b) High-resolution profiling and discovery of planarian small RNAs. Proc Natl Acad Sci U S A 106: 11546-11551. doi: $10.1073 /$ pnas.0905222106

Gonzalez-Estevez C, Arseni V, Thambyrajah RS, Felix DA, Aboobaker AA (2009) Diverse miRNA spatial expression patterns suggest important roles in homeostasis and regeneration in planarians. Intl J Develop Biol 53: 493-505. http://doi.org/10.1387/ijdb.082825cg

He L, Hannon GJ (2004) Micrornas: Small RNAs with a big role in gene regulation. Nature Reviews Genetics 5: 522-531. http://doi. org/10.1038/nrg1379

Hubert A, Henderson JM, Ross KG, Cowles MW, Torres J, Zayas RM (2013) Epigenetic regulation of planarian stem cells by the SET1/ MLL family of histone methyltransferases. Epigenetics 8: 79-91. http://doi.org/10.4161/epi.23211

Johnson CD, Esquela-Kerscher A, Stefani G, Byrom N, Kelnar K, Ovcharenko D, Wilson M, Wang XW, Shelton J, Shingara J, Chin L, Brown D, Slack FJ (2007) The let-7 MicroRNA represses cell proliferation pathways in human cells. Cancer Res 67: 7713-7722. http://doi.org/10.1158/0008-5472.CAN-07-1083

Juliano C, Wang JQ, Lin HF (2011) Uniting germline and stem cells: the function of Piwi proteins and the piRNA pathway in diverse organisms. Annual Rev Genet 45: 447-469. http://doi.org/10.1146/ annurev-genet-110410-132541

Kang H, Alvarado AS (2009) Flow cytometry methods for the study of cell-cycle parameters of planarian stem cells. Develop Dynamics 238: 1111-1117. http://doi.org/10.1002/dvdy.21928

Kao D, Felix D, Aboobaker A (2013) The planarian regeneration transcriptome reveals a shared but temporally shifted regulatory program between opposing head and tail scenarios. BMC Genomics 14: Artn 797. http://doi.org/10.1186/1471-2164-14-797

Kennell JA, Gerin I, MacDougald OA, Cadigan KM (2008) The microRNA miR-8 is a conserved negative regulator of Wnt signaling. Proc Natl Acad Sci U S A 105: 15417-15422. http://doi.org/10.1073/ pnas.0807763105

Labbe RM, Irimia M, Currie KW, Lin A, Zhu SJ, Brown DDR, Ross EJ, Voisin V, Bader GD, Blencowe BJ, Pearson BJ (2012) A comparative transcriptomic analysis reveals conserved features of stem cell pluripotency in planarians and mammals. Stem Cells 30: 1734 1745. http://doi.org/10.1002/stem.1144

Li TG, Kelly WG (2011) A role for Set1/MLL-Related components in epigenetic regulation of the Caenorbabditis elegans germ line. Plos Genetics 7: ARTN e1001349. http://doi.org/10.1371/journal. pgen.1001349

Li YQ, Zeng A, Han XS, Wang C, Li G, Zhang ZC, Wang JY, Qin YW, Jing Q (2011) Argonaute-2 regulates the proliferation of adult stem cells in planarian. Cell Res 21: 1750-1754. http://doi. org/10.1038/cr.2011.151

Lobo D, Beane WS, Levin M (2012) Modeling planarian regeneration: a primer for reverse-engineering the worm. Plos Comp Biol 8: ARTN e1002481. http://doi.org/10.1371/journal.pcbi.1002481

Lu YC, Smielewska M, Palakodeti D, Lovci MT, Aigner S, Yeo GW, Graveley BR (2009) Deep sequencing identifies new and regulated microRNAs in Schmidtea mediterranea. RNA-a Publication of the RNA Society 15: 1483-1491. http://doi.org/10.1261/rna.1702009

MacDonald BT, Tamai K, He X (2009) Wnt/beta-catenin signaling: components, mechanisms, and diseases. Dev Cell 17: 9-26. http:// doi.org/10.1016/j.devcel.2009.06.016

Morris KV, Mattick JS (2014) The rise of regulatory RNA. Nature Rev Genet 15: 423-437. http://doi.org/10.1038/nrg3722
Newmark PA, Alvarado AS (2000) Bromodeoxyuridine specifically labels the regenerative stem cells of planarians. Develop Biol 220: 142153. http://doi.org/10.1006/dbio.2000.9645

Newmark PA, Alvarado AS (2002) Not your father's planarian: A classic model enters the era of functional genomics. Nat Rev Genet 3: 210-219. http://doi.org/10.1038/nrg759

Newmark PA, Reddien PW, Cebria F, Sanchez Alvarado A (2003) Ingestion of bacterially expressed double-stranded RNA inhibits gene expression in planarians. Proc Natl Acad Sci U S A 100 (Suppl 1): 11861-11865. http://doi.org/10.1073/pnas.1834205100

Orii H, Mochii M, Watanabe K (2003) A simple "soaking method" for RNA interference in the planarian Dugesia japonica. Dev Genes Evol 213: 138-141. http://doi.org/10.1007/s00427-003-0310-3

Palakodeti D, Smielewska M, Graveley BR (2006) MicroRNAs from the planarian Schmidtea mediterranea: A model system for stem Cell Biol. RNA-a Publication of the RNA Society 12: 1640-1649. http://doi. org/10.1261/rna.117206

Palakodeti D, Smielewska M, Lu YC, Yeo GW, Graveley BR (2008) The PIWI proteins SMEDWI-2 and SMEDWI-3 are required for stem cell function and piRNA expression in planarians. RNA 14: 1174-1186.

Pearson BJ, Eisenhoffer GT, Gurley KA, Rink JC, Miller DE, Sanchez Alvarado A (2009) Formaldehyde-based whole-mount in situ hybridization method for planarians. Dev Dyn 238: 443-450. http:// doi.org/10.1002/dvdy.21849

Pellettieri J, Alvarado AS (2007) Cell turnover and adult tissue homeostasis: From humans to planarians. Ann Rev Genet 41: 83-105. http://doi.org/10.1146/annurev.genet.41.110306.130244

Petersen CP, Reddien PW (2008) Smed-betacatenin-1 is required for anteroposterior blastema polarity in planarian regeneration. Science 319: 327-330. doi: 10.1126/science. 1149943

Petersen CP, Reddien PW (2009) Wnt Signaling and the polarity of the primary body axis. Cell 139: 1056-1068. http://doi.org/10.1016/j. cell.2009.11.035

Qin YF, Zhao JM, Bao ZX, Zhu ZY, Mai J, Huang YB, Li JB, Chen G, Lu P, Chen SJ, Su LL, Fang HM, Lu JK, Zhang YZ, Zhang ST (2012) Identification of small non-coding RNAs in the planarian Dugesia japonica via deep sequencing. Genomics 99: 315-321. http:// doi.org/10.1016/j.ygeno.2012.03.001

Reddien PW, Alvarado AS (2004) Fundamentals of planarian regeneration. Annual Review of Cell and Developmental Biology 20: 725-757. http://doi.org/10.1146/annurev.cellbio.20.010403.095114

Reddien PW, Bermange AL, Murfitt KJ, Jennings JR, Sanchez Alvarado A (2005a) Identification of genes needed for regeneration, stem cell function, and tissue homeostasis by systematic gene perturbation in planaria. Dev Cell 8: 635-649. http://doi.org/10.1016/j.devcel.2005.02.014

Reddien PW, Oviedo NJ, Jennings JR, Jenkin JC, Sanchez Alvarado A (2005b) SMEDWI-2 is a PIWI-like protein that regulates planarian stem cells. Science 310: 1327-1330. doi: 10.1126/science.1116110

Resch AM, Palakodeti D (2012) Small RNA pathways in Schmidtea mediterranea. Intl J Develop Biol 56: 67-74. http://doi.org/10.1387/ ijdb.113436ar

Rink JC (2013) Stem cell systems and regeneration in planaria. Develop Genes Evol 223: 67-84. http://doi.org/10.1007/s00427-012-0426-4

Robb SMC, Alvarado AS (2002) Identification of immunological reagents for use in the study of freshwater planarians by means of whole-mount immunofluorescence and confocal microscopy. Genesis 32: 293-298. http://doi.org/10.1002/gene.10087

Roberts-Galbraith RH, Newmark PA (2015) On the organ trail: insights into organ regeneration in the planarian. Curr Opin Genet Develop 32: 37-46. http://doi.org/10.1016/j.gde.2015.01.009

Ross E, Blair D, Guerrero-Hernandez C, Sanchez Alvarado A (2016) Comparative and transcriptome analyses uncover key aspects of coding- and long non-coding RNAs in flatworm mitochondrial genomes. G3 (Bethesda). http://doi.org/10.1534/g3.116.028175

Ross KG, Omuro KC, Taylor MR, Munday RK, Hubert A, King RS, Zayas RM (2015) Novel monoclonal antibodies to study tissue regeneration in planarians. BMC Develop Biol 15: Artn 2. http://doi. org/10.1186/S12861-014-0050-9

Rossi L, Salvetti A, Batistoni R, Deri P, Gremigni V (2008) Planarians, a tale of stem cells. Cell Mol Life Sci 65: 16-23. http://doi. org/10.1007/s00018-007-7426-y

Rouhana L, Weiss JA, Forsthoefel DJ, Lee H, King RS, Inoue T, Shibata N, Agata K, Newmark PA (2013) RNA interference by feeding in vitro-synthesized double-stranded RNA to planarians: methodology and dynamics. Dev Dyn 242: 718-730. http://doi.org/10.1002/ dvdy. 23950

Rouhana L, Weiss JA, King RS, Newmark PA (2014) PIWI homologs mediate Histone $\mathrm{H} 4 \mathrm{mRNA}$ localization to planarian chromatoid bodies. Development 141: 2592-2601. http://doi.org/10.1242/ dev.101618

Roush S, Slack FJ (2008) The let-7 family of microRNAs. Trends Cell Biol 18: 505-516. http://doi.org/10.1016/j.tcb.2008.07.007

Sanchez-Alvarado A (2006) Planarian regeneration: Its end is its beginning. Cell 124: 241-245. http://doi.org/10.1016/j.cell.2006.01.012 
Sanchez Alvarado A (2012) Q\&A: what is regeneration, and why look to planarians for answers? BMC Biol 10: 88. http://doi. org/10.1186/1741-7007-10-88

Sasidharan V, Lu YC, Bansal D, Dasari P, Poduval D, Seshasayee A, Resch AM, Graveley BR, Palakodeti D (2013) Identification of neoblast- and regeneration-specific miRNAs in the planarian Schmidtea mediterranea. RNA-a Publication of the RNA Society 19: 1394-1404. http://doi.org/10.1261/rna.038653.113

Scimone ML, Kravarik KM, Lapan SW, Reddien PW (2014) Neoblast specialization in regeneration of the planarian Schmidtea medsiterranea. Stem Cell Reports 3: 339-352. http://doi.org/10.1016/j.stemcr.2014.06.001

Thomson T, Lin HF (2009) The biogenesis and function of PIWI proteins and piRNAs: progress and prospect. Ann Rev Cell Develop Biol 25: 355-376. http://doi.org/10.1146/annurev.cellbio.24.110707.175327

Tian QN, Bao ZX, Lu P, Qin YF, Chen SJ, Liang F, Mai J, Zhao JM, Zhu ZY, Zhang YZ, Zhang ST (2012) Differential expression of microRNA patterns in planarian normal and regenerative tissues. Mol Biol Reports 39: 2653-2658. http://doi.org/10.1007/s11033-0111018-5

Timmons L, Court DL, Fire A (2001) Ingestion of bacterially expressed dsRNAs can produce specific and potent genetic interference in
Caenorhabditis elegans. Gene 263: 103-112. http://doi.org/10.1016/ S0378-1119(00)00579-5

van Wolfswinkel JC, Wagner DE, Reddien PW (2014) Single-cell analysis reveals functionally distinct classes within the planarian stem cell compartment. Cell Stem Cell 15: 326-339. http://doi.org/10.1016/j. stem.2014.06.007

Vogg MC, Owlarn N, Rico YAP, Xie J, Suzuki Y, Gentile L, Wu W, Bartscherer K (2014) Stem cell-dependent formation of a functional anterior regeneration pole in planarians requires Zic and Forkhead transcription factors. Develop Biol 390: 136-148. http://doi. org/10.1016/j.ydbio.2014.03.016

Weick EM, Miska EA (2014) piRNAs: from biogenesis to function. Development 141: 3458-3471. http://doi.org/10.1242/dev.094037

Wulczyn FG, Smirnova L, Rybak A, Brandt C, Kwidzinski E, Ninnemann O, Strehle M, Sefler A, Schumacher S, Nitsch R (2007) Posttranscriptional regulation of the let- 7 microRNA during neural cell specification. Faseb J 21: 415-426. http://doi.org/10.1096/fj.06$6130 \mathrm{com}$

Zhu SJ, Hallows SE, Currie KW, Xu C, Pearson BJ (2015) A mex3 homolog is required for differentiation during planarian stem cell lineage development. Elife 4. http://doi.org/10.7554/eLife.07025 